\title{
Proceeding
}

Supplementary Issue: Summer Conferences of Sports Science. Costa Blanca Sports Science Events, 25-26 September 2020. Alicante, Spain.

\section{Physical activity as protective factor against COVID-19 disease}

\author{
ALBERTO AMETTA ${ }^{1}$, VINCENZO CRISTIAN FRANCAVILLA ${ }^{2} \Delta$, RITA POLITO3,4, MARCELLINO \\ MONDA ${ }^{5}$, ANTONIETTA MESSINA ${ }^{5}$, VINCENZO MONDA ${ }^{5}$, FRANCESCO SESSA ${ }^{3}$, AURORA DANIELE ${ }^{6}$, \\ GIOVANNI MESSINA ${ }^{3}$ \\ ${ }^{1}$ Department of Economy, University of Foggia, Italy \\ 2School of Engineering, Architecture, and Motor Sciences, Kore University of Enna, Enna, Italy \\ ${ }^{3}$ Department of Clinical and Experimental Medicine, University of Foggia, Italy \\ ${ }^{4}$ Department of Public Health, University of Naples "Federico II", Naples, Italy \\ ${ }^{5}$ Department of Experimental Medicine, Section of Human Physiology and Unit of Dietetic and Sport Medicine, Luigi \\ Vanvitelli University of Campania, Naples, Italy \\ ${ }^{6}$ Department of Biological and Pharmaceutical Environmental Sciences and Technologies, Luigi Vanvitelli University \\ of Campania, Naples, Italy
}

\begin{abstract}
The Coronavirus Pandemic has forced millions of people around the world to look at home. This resulted, as a consequence, in a remodelling of the lifestyle; in this scenario the correct nutrition combined with regular physical activity becomes fundamental for health. Although the sedentary lifestyle of a few weeks involves risks such as lowering the immune system, it favours overweight and obesity, high blood pressure, metabolic disorders, depression and anxiety, and in some subjects they react to the risk of onset of cardiovascular disease, diabetes and other diseases. The importance of healthy lifestyle is crucial to prevent also viral infection. Indeed, as reported by many data literature, during lung infections, IL- 6 and TNF-a create the pathway between adipose tissue and lung system demonstrating the important involvement of adipose tissue in lung diseases. In obese condition, adipose tissue endocrine function is altered. There is an imbalance in the production of pro-inflammatory cytokines such as IL-6 and TNF-a and anti-inflammatory mediators such as IL-10. In the light of these evidences, the immune response is influenced by nutritional status and by physical activity which are able to reduce proinflammatory mediators and increase anti-inflammatory mediators such as IL-10. In addition, the power of viral infection is influenced by host predisposition. For these reasons, a correct lifestyle, and physical activity are a valid strategy in the prevention and treatment of not metabolic diseases also of inflammatory diseases.
\end{abstract}

Keywords: Coronavirus pandemic; Lifestyle; Health; Metabolic diseases; Inflammatory diseases.

Cite this article as:

Ametta, A., Francavilla, V.C., Polito, R., Monda, M., Messina, A., Monda, V., Sessa, F., Daniele, A., \& Messina, G. (2020). Physical activity as protective factor against COVID-19 disease. Journal of Human Sport and Exercise, 15(4proc), S987S991. doi:https://doi.org/10.14198/jhse.2020.15.Proc4.01

Corresponding author. School of Engineering, Architecture, and Motor Sciences, Kore University of Enna, Enna, Italy.

E-mail: vincenzo.francavilla@unikore.it

Abstract submitted to: Spring Conferences of Sports Science. Costa Blanca Sports Science Events, 19-20 June 2020. Alicante, Spain.

JOURNAL OF HUMAN SPORT \& EXERCISE ISSN 1988-5202

(C) Faculty of Education. University of Alicante

doi:10.14198/jhse.2020.15.Proc4.01 


\section{INTRODUCTION}

Coronaviruses are a family of viruses including a-coronavirus, $\beta$-coronavirus, $y$-coronavirus, and deltacoronavirus. In human infection with highly virulent respiratory viruses, such as avian influenza H5N1, H7N9, Severe Acute Respiratory Syndrome (SARS) coronavirus, and Coronavirus Disease-19 (Covid-19) immunopathogenesis caused by hyperinduction of proinflammatory cytokines may play an important role in the disease progression and the mortality (Zhao et al. 2020). Li et all reported that COVID-19 caused the complete destruction of the pulmonary parenchyma including interstitial inflammation and extensive consolidation, similar to the previously reported coronavirus infection (Li et al, 2017). It is known that the viral infection are influenced also by host predisposition and host health e/or nutrition. Certainly, the nutrition and physical activity play an important role in the establishment of viral inflammation. In particular, Arslan et al. reported that nutrition and also the metabolic pathways are strongly involved and influenced by viral infection (Arslan et al, 2019). Indeed, in order to succumb hosts, viruses have evolved strategies to manipulate specific cellular metabolic pathways that aid the production of viral particles (Messina $\mathrm{G}$ et al., 2015; Moscatelli et al., 2016). Viruses need to breach a complex network of metabolic intrinsic factors and microenvironment established within the host cells. For absolute survival, proliferation, and propagation inside the host cell, viruses modulate certain metabolic pathways to destabilize the host metabolism. These alterations in host metabolic signalling as a result of virus-host interaction generate a favourable environment for the viral pathogens. An important pathway involved by virus infection is glucose metabolism and pathway. It is well known that during virus infection, there is an establishment of the acute inflammation, recruiting of innate and adaptative immune cells (Moscatelli et al, 2015; Orban et al., 2014; Pomara et al., 2020). In particular, T-cells and macrophages are capable of viral clearance by phagocytosis. Many viruses influenced glucose metabolism in these immune cells, through a competition mechanism (Wang et al., 2016; Davison et al., 2016). It is well known that the immune system is crucial for the defence against organisms that cause infections and against toxic products that may be released from the infectious agents. In addition, many data literatures showed the essential role of IL-6 to mount a proper immune response during some viral infections in pulmonary tract, others link this cytokine with exacerbation of viral disease. These latter findings lend support to the hypothesis that upregulation of IL-6 during certain viral infections may promote virus survival and/or exacerbation of clinical disease. Indeed, IL-6 has a pleotropic function and it is produced in response to tissue damage and infections. In particular, in pulmonary seat, innate and adaptative immune cells proliferation is strongly influenced by this cytokine (Messina et al, 2020) Furthermore, it is reported that IL-6 is an important factor for survival of mice with viral infection (Santantonio et al, 2020). This cytokine promotes optimal regulation of the T-cell response, inflammatory resolution, tissue remodelling promoting lung repair, migration and phagocytic activities of macrophages, and it prevents viral-induced apoptosis in lung epithelial cells. During, viral infection, it is reported that the role of the predisposition of the host subject is also important, also due to his state of health and nutrition (Messina et al, 2020; Santantonio et al, 2020; Pomara et al., 2020). Indeed, it is well known that the white adipose tissue is considered an endocrine source of biologically active substances with local and/or systemic action called adipokines. An inappropriate secretion of adipokines seems to participate in the pathogenesis of obesity-related diseases including endothelial dysfunction, inflammation and atherosclerosis (Messina et al., 2018). In this scenario, the host predisposition to viral infection is the most important factors. Indeed, a healthy lifestyle characterized by correct nutrition and physical activity may be essential to protect against viral infection (Francavilla et al, 2007; Francavilla et al, 2018; Francavilla et al, 2016; Salerno et al., 2020). In the light of these evidences, the aim of this review is to discuss the beneficial effects of physical activity in viral infections. 


\section{PHYSICAL ACTIVITY IN VIRAL INFECTION}

Physical activity as many beneficial effects on healthy status. It stimulates immune processes and metabolic pathways, inducing physical and mental wellness. In addition, physical activity prevent many diseases such as obesity, type 2 diabetes, cardiovascular disease and cancer (Messina et al, 2015).

The molecular mechanisms through which physical activity reduces the risk and severity of these diseases are multiple and complex. The regulation of immune and inflammatory response by physical activity is important also in the protection by viral infection. The physical activity activates immune system, reducing the risk of severe complications following microbial and viral infections (Di Maio et al., 2020; Sessa et al., 2020). Many data literature reported that physical activity influenced the immune response and also the intensity and duration of exercise influenced immune and inflammatory responses (Warren et al, 2015; Luzi et al 2020; Pedersen et al, 2008). It is well known that regular physical activity leads to positive effects that improve both immune defence and metabolic health (Francavilla et al, 2018; Bianco et al 2018). Regular physical activity stimulates the immune system, improving the activity and the antimicrobial action of macrophages and promoting the activation and production of anti-inflammatory mediators such IL-10 (Francavilla et al, 2013; Francavilla et al, 2015; Francavilla et al, 2017). These positive changes improve vitality of immune-cells against infectious pathogens and protect or mitigate the symptoms of infectious diseases. Many data literature reported also that the healthy lifestyle is able to protect against viral infection. Indeed, a recent study in obese and non-obese mice with H1N1 viral infection (Influenza A Virus, IAV), the authors demonstrated that physical activity reverted the immune system alterations associated with obesity in the host's immune defence, in addition it is demonstrated that the physical activity stimulates the immune system response, resulted impaired when compared to non-obese (Santantonio et al., 2002; Ohashi et al., 2014; Bermon et al., 2017). Furthermore, the host predisposition is an important factor in viral infection, indeed, it is demonstrated that the severity of symptoms of Coronavirus infection is strongly associated with the health status of individuals before the infection, indeed the efficacy of a regular physical activity performed before the infection, able to reduce or mitigate the severity of disease and the severe inflammation in subjects with Coronavirus infection. It is well known that physical activity induced anti-inflammatory cytokines production such as IL-10 and IL-6 suggesting the protective role of physical activity in viral infection and then in COVID-19 diseases (Messina et al., 2020). Indeed, it is well known that physical activity has beneficial effects on lung function, reducing the risk of infections and respiratory diseases.

\section{CONCLUSIONS}

Given the many beneficial effects on healthy status, on metabolic and inflammatory processes, also in viral infection the healthy lifestyle is the first force. Covid-19 is the lung viral infection leading to pro-inflammatory cytokines production and to impaired immune cells production. In this scenario, the host predisposition is important factor in viral infection, indeed, the severity of Coronavirus infection is strongly associated with the health status of individuals before the infection. For these reasons, the correct nutrition and the regular physical activity are able to protect by viral infection.

\section{REFERENCES}

Andrew Wang, et al. (2016). "Opposing Effects of Fasting Metabolism on Tissue Tolerance in Bacterial and Viral Inflammation". Cell.

Arslan Mehboob Arslan, et al. (2019). "Impact of Viruses on Host Metabolism". Host and Viruse. https://doi.org/10.17582/journal.hv/2019/6.2.23.29 
Bermon S, Castell LM, Calder PC, et al. (2017). Consensus Statement Immunonutrition and Exercise. Exercise immunology review; 23:8-50.

Bertozzi, G., Sessa, F., Albano, G. D., Sani, G., Maglietta, F., Roshan, M. H. K., et al. (2017). The Role of Anabolic Androgenic Steroids in Disruption of the Physiological Function in Discrete Areas of the Central Nervous System. Mol. Neurobiol., 1-9. https://doi.org/10.1007/s12035-017-0774-1

Bianco A, Gentile A, Boca S, et al. (2018). An exploratory analysis of factors associated with healthrelated physical fitness in adolescents. Sustainability; 10:1847. https://doi.org/10.3390/su10061847

Cristian V Francavilla, Francesco Sessa, Monica Salerno, Giuseppe D Albano, Ines Villano, et al. (2018). Influence of Football on Physiological Cardiac Indexes in Professional and Young Athletes. Front Physiol.; 9:153. https://doi.org/10.3389/fphys.2018.00153

Davison G, Kehaya C, Wyn Jones A. (2016). Nutritional and Physical Activity Interventions to Improve Immunity. American journal of lifestyle medicine; 10:152-169. https://doi.org/10.1177/1559827614557773

Di Maio, G., Monda, V., Messina, A., Villano, I., Francavilla, V.C. (2020). Physical activity and modification of lifestyle induce benefits on the health status. Acta Medica Mediterranea. 36(3), pp. 1913-1919.

Francavilla G, Francavilla C. (2013). Physical exercise is therapy. Med Sport; 66:625-8.

Francavilla C, Francavilla A, Braschi M, et al. (2007). Physical exercise and sport activities in patients with and without coronary heart disease. Monadi Arch Chest Dis; 87-95.

Francavilla VC, Bongiovanni T, Genovesi F, Minafra P, Francavilla G. (2015). Localized bioelectrical impedance analysis: how useful is it in the follow-up of muscle injury? A case report. Med Sport; 68:323-34.

Francavilla VC, Bongiovanni T, Todaro L, Di Pietro V, Francavilla G. (2017). Probiotic supplements and athletic performance: a review of the literature. Med Sport; 70(2):247-59. https://doi.org/10.23736/S0025-7826.17.03037-X

Francavilla C, Bongiovanni T, Todaro L, Genovesi F, Francavilla G. (2016). Risk factors, screening tests and prevention strategies of muscle injuries in elite soccer players: a critical review of the literature. Med Sport; 69: 134-50.

Francavilla C, Vitale F, Ciaccio Marcello et al. (2018). Use of saliva in alternative to serum sampling to monitor biomarkers modification in professional soccer players. Frontiers in Phsiology. https://doi.org/10.3389/fphys.2018.01828

Giovanni Messina, et al. (2020). Functional Role of Dietary Intervention to Improve the Outcome of COVID-19: A Hypothesis of Work. Int. J. Mol. Sci., 21(9), 3104. https://doi.org/10.3390/ijms21093104

Helieh S. Oz. (2017). "Nutrients, Infectious and Inflammatory Diseases". Nutrients. https://doi.org/10.1155/2017/6134909

Li Y, et al. (2017). Coronavirus Infections in the Central Nervous System and Respiratory Tract Show Distinct Features in Hospitalized Children.

Luzi L., MG Radaelli. (2020). Influenza and obesity: its odd relationship and the lessons for COVID-19 pandemic Acta Diabetologica. 57, 759-764. https://doi.org/10.1007/s00592-020-01522-8

Messina, A., Bitetti, I., Precenzano, F., lacono, D., Messina, G., Roccella, M., et al. (2018). Non-rapid eye movement sleep parasomnias and migraine: A role of orexinergic projections. Front. Neurol. 9. https://doi.org/10.3389/fneur.2018.00095

Messina, G., Zannella, C., Monda, V., Dato, A., Liccardo, D., De Blasio, S., et al. (2015). The beneficial effects of coffee in human nutrition. Biol. Med. 7:4.

Moscatelli, F., Messina, G., Valenzano, A., Monda, V., Viggiano, A., Messina, A., et al. (2016). Functional assessment of corticospinal system excitability in karate athletes. PLoS One. https://doi.org/10.1371/journal.pone.0155998 
Moscatelli, F., Messina, G., Valenzano, A., Petito, A., Triggiani, A. I., Ciliberti, M. A. P., et al. (2015). Relationship between RPE and blood lactate after fatiguing handgrip exercise in taekwondo and sedentary subjects. Biol. Med. 1:2.

Ohashi, K.; Shibata, R.; Murohara, T.; Ouchi, N. (2014). Role of anti-inflammatory adipokines in obesityrelated diseases. Trends Endocrinol. Metab., 25, 348-355. https://doi.org/10.1016/.tem.2014.03.009

Orban, G., Bombardi, C., Marino Gammazza, A., Colangeli, R., Pierucci, M., Pomara, C., et al. (2014). Role(s) of the 5-HT2C receptor in the development of maximal dentate activation in the hippocampus of anesthetized rats. CNS Neurosci. Ther. https://doi.org/10.1111/cns.12285

Pedersen BK, Febbraio MA. (2008). Muscle as an endocrine organ: focus on muscle-derived interleukin6. Physiol Rev.; 88:1379-406. https://doi.org/10.1152/physrev.90100.2007

Pomara, C., Volti, G. L., and Cappello, F. (2020). COVID-19 Deaths: Are We Sure It Is Pneumonia? Please, Autopsy, Autopsy, Autopsy! J. Clin. Med. 2020, Vol. 9, Page 1259 9, 1259. https://doi.org/10.3390/jem9051259

Salerno, M., Sessa, F., Piscopo, A., Montana, A., Torrisi, M., Patanè, F., et al. (2020). No Autopsies on COVID-19 Deaths: A Missed Opportunity and the Lockdown of Science. J. Clin. Med. https://doi.org/10.3390/jcm9051472

Sessa, F., Bertozzi, G., Cipolloni, L., Baldari, B., Cantatore, S., D'Errico, S., et al. (2020). ClinicalForensic Autopsy Findings to Defeat COVID-19 Disease: A Literature Review. J. Clin. Med. https://doi.org/10.3390/jcm9072026

Teresa A Santantonio, Giovanni Messina. (2020). Update on Coronavirus Disease 2019 (COVID-19). The Open Neurology Journal, 14. https://doi.org/10.2174/1874205X02014010004

Warren KJ, Olson MM, Thompson NJ. (2015). Exercise improves host response to influenza viral infection in obese and non-obese mice through different mechanisms. PLoS ONE 25:1-27. https://doi.org/10.1371/journal.pone.0129713

Zhao W, Zhong Z, Xie X, Yu Q, Liu J. (2020). Relation Between Chest CT Findings and Clinical Conditions of Coronavirus Disease (COVID-19) Pneumonia: A Multicenter Study. AJR Am J Roentgenol. 2020 Mar 3:1-6. https://doi.org/10.2214/AJR.20.22976 